\title{
Thermogravimetric Investigation of the Influence of Colloidal Phase on the Processing Properties of Crude Oil Residues
}

\author{
H. Laux ${ }^{1}$, T. Butz ${ }^{1}$ and I. Rahimian ${ }^{1}$ \\ 1 German Petroleum Institute, Walther-Nernst-Str. 7, D-38678 Clausthal-Zellerfeld-Germany \\ e-mail: Postmaster@ife-clausthal.de
}

\begin{abstract}
Résumé - Analyse thermogravimétrique de l'influence de la phase colloïdale sur les propriétés de traitement des résidus pétroliers - Un résidu pétrolier atmosphérique, un résidu de distillation sous vide, un résidu de viscoréduction, les fractions maltènes qui en sont séparées, des mélanges du résidu atmosphérique avec le résidu sous vide et un résidu de l'extraction surcritique du résidu sous vide, ainsi que des résidus mélangés avec des agents dispersants d'asphaltes ont été soumis à la thermogravimétrie, à trois vitesses de chauffage différentes. On en a déterminé les énergies d'activation pour la réaction de décomposition. L'énergie d'activation correspond à l'enthalpie de vaporisation, pour des températures inférieures ou égales à $400^{\circ} \mathrm{C}$, et à l'enthalpie de séparation, pour des températures supérieures à $400^{\circ} \mathrm{C}$. L'intensité des forces d'interaction, agissant entre la phase colloïdale dispersée et les composants du milieu de dispersion, en est déduite. On constate l'influence de la concentration de la phase dispersée ainsi que l'influence significative de la stabilité de celle-ci sur les résidus, et particulièrement sur l'enthalpie de vaporisation. Afin d'apprécier la stabilité des résidus, le point de floculation a été determiné. Les dépendances de l'enthalpie de vaporisation obtenues se reflètent dans les produits de distillation, surtout pour une température de 300 à $400^{\circ} \mathrm{C}$. Elles s'expriment toutefois aussi dans le résidu ATG (analyse gravimétrique) à $500{ }^{\circ} \mathrm{C}$. Ainsi la thermogravimétrie s'avère-t-elle être une méthode efficace de détermination d'importants paramètres du traitement des résidus pétroliers, prenant en compte l'influence de la phase colloïdale dispersée de ces mélanges complexes. Mots-clés: résidus pétroliers, asphaltènes, stabilité colloïdale, thermogravimétrie, points de floculation, enthalpie de vaporisation.
\end{abstract}

\begin{abstract}
Thermogravimetric Investigation of the Influence of Colloidal Phase on the Processing Properties of Crude Oil Residues — An atmospheric residue, a vacuum residue, a visbreaking residue, the maltene fractions of the residues, mixtures of the atmospheric residue with the vacuum residue and the residue from the supercritical extraction of the vacuum residue as well as residues mixed with dispersing agents were investigated by thermogravimetry at three different heating rates. From that, the activation energies of the weight loss were estimated. At temperatures up to about $400^{\circ} \mathrm{C}$ the activation energy corresponds to the evaporation enthalpy, above $400^{\circ} \mathrm{C}$ to the cracking energy. Comparing the results the strenght of the interactions between colloid disperse phase and the components of dispersion medium was evaluated. It was found that besides the content of colloid disperse phase its stability has a significant influence on the properties of the residues, especially on the evaporation enthalpy. The stability of residues was investigated by the flocculation point determination. The obtained dependencies of evaporation enthalpies are also reflected in the yields of distillates and in the thermogravimetric residues at $500^{\circ} \mathrm{C}$. Thermogravimetry proves to be an effective method for the determination of important parameters of processing of crude oil residues considering the influence of the colloidal character of these complex mixtures.
\end{abstract}

Keywords: crude oil residues, asphaltenes, colloidal stability, thermogravimetry, flocculation points, evaporation enthalpy. 


\section{INTRODUCTION}

Crude oil residues are complex mixtures of different organic compounds characterised by the existence of a colloidal disperse phase. The formation of the colloidal disperse phase is based on the low solubility of the asphaltenes compounds which are insoluble in $n$-alkanes as $n$-pentane and $n$-heptane but soluble in toluene. The asphaltenes associate to crystallites as nucleus of colloid particles. The solvation of these nuclei by resins and other compounds determines the stability of the colloid particles and hinders the further aggregation.

The processing characteristics of crude oils are adversely influenced by the colloidal asphaltene phase. Depending on colloidal stability the colloidal phase is among other things the reason of fouling, coke formation and deactivation of catalysts, especially at the conversion of residues (Zou and Lin, 1994). Mixing of different products and the addition of dispersing agents are possibilities to stabilise the colloidal disperse phase and by that to improve the processing conditions.

But the effectiveness of such measures is difficult to assess, because the colloidal stability depends on different factors as the solubility parameters of asphaltenes and of dispersion medium (Laux et al., 1997a).

Kopsch (1995) has shown that information on the processing behaviour of crude oils and crude oil residues at higher temperatures can be obtained by thermogravimetry analysis (TGA). Among other things it is possible to calculate the activation energy of evaporation and cracking examining both processes as first order reactions:

$$
A \rightarrow B
$$

In this case the conversion is a function as described by Equation (2):

$$
q\left(\frac{\mathrm{d} x}{\mathrm{~d} T}\right)=A\left[\exp \left(-\frac{E}{\mathrm{R} T}\right)\right](1-x)
$$

where:

$q$ rate of heating

$x$ weight loss

$A$ frequency factor

$E$ activation energy

$\mathrm{R}$ universal gas constant

$T$ temperature

Using the thermogravimetric curves from at least three test runs at different heating rates, $A$ and $E$ can be calculated on the basis of the method according to Flynn and Wall (1966). In the temperature region below $400^{\circ} \mathrm{C}$ the activation energy corresponds to the evaporation enthalpy at the thermogravimetric conditions; above $400^{\circ} \mathrm{C}$ activation energy is determined by the cracking enthalpy.
It was found that the activation energies depend on the interaction forces between the colloidal disperse phase and components of the dispersion medium, too (Laux and Kopsch, 1996; Laux et al., 1998). In this way the influence of colloidal disperse phase on the processing behaviour of residues can be evaluated.

In this article the results of thermogravimetric investigations of different residues in dependence on the composition and the colloidal stability are presented and discussed.

\section{EXPERIMENTAL}

Three residues were chosen to investigate the influence of colloidal disperse phase on the thermogravimetric behaviour: an atmospheric residue, a vacuum residue and the atmospheric residue of the visbreaking product of the vacuum residue.

These residues were fractionated into asphaltenes, resins and dispersion medium according to Neumann and Wilkens (1974) by precipitation of the complete colloids with ethyl acetate. Afterwards, the resins were extracted by $n$-pentane and the asphaltenes by toluene. The asphaltenes were characterised by fractionation in three solubility classes according to Zenke (1989): asphaltenes were dissolved in boiling cyclohexane and subfractions were precipitated by stepwise addition of isooctane. At the cyclohexane/isooctane ratio 1:1 the low soluble fraction precipitated and at 1:2 the middle soluble fraction. The easily soluble fraction remains dissolved at this ratio.

Supercritical fluid extraction (SFE) was applied to prepare another subfraction of vacuum residue using $\mathrm{CO}_{2}$ at $40^{\circ} \mathrm{C}$ and $14 \mathrm{MPa}$ in the first step and $\mathrm{CO}_{2}+$ isooctane as entrainer at $100^{\circ} \mathrm{C}$ and $30 \mathrm{MPa}$ in the second step. The resulting extraction residue was enriched with aromatic and polar compounds in comparison to the vacuum residue.

The colloidal composition of the residues are given in Table 1.

TABLE 1

Colloidal composition of residues (wt \%)

\begin{tabular}{l|c|c|c}
\hline \multicolumn{1}{c|}{ Residue } & Atmospheric & Vacuum & Visbreaking \\
\hline Dispersion medium & 96.1 & 91.5 & 91.1 \\
\hline Resins & traces & traces & traces \\
\hline Asphaltenes & 3.2 & 8.2 & 8.9 \\
Asphaltene subfractions & & & \\
$\quad$ Easily soluble & 21.8 & 27.6 & 1.3 \\
$\quad$ Middle soluble & 22.0 & 15.5 & 0.4 \\
$\quad$ Low soluble & 56.1 & 56.4 & 97.0 \\
\hline Loss & 0.7 & 0.3 & 0 \\
\hline
\end{tabular}


Further information about the composition can be taken from Laux et al., 1999.

Besides the original residues the following fractions and mixtures were subjected to thermogravimetry:

- the maltene fractions of residues;

- mixtures of the atmospheric and vacuum residues;

- mixtures of the atmospheric residue with supercritical extraction residue from the vacuum residue;

- mixtures of the atmospheric resp. the visbreaking residues with different amounts of two dispersing agents (one of phenolic basis, one of amine amide basis).

Thermogravimetry was carried out using the $T A$ Instruments thermal analyzer 951. The sample size for the analysis was 8 to $10 \mathrm{mg}$. The heating rates were 5, 10 and $20 \mathrm{~K} / \mathrm{min}$ at a stream of $\arg$ on of $50 \mathrm{~cm}^{3} / \mathrm{min}$. The kinetic parameters of evaporation and cracking were calculated by the TA Instruments software according to Flynn and Wall (1996).

The results of the thermogravimetric analysis of the $n$-alkanes with carbon numbers 18, 32, 44 and 54 were used to ascertain the correlation between TGA-temperature and normal boiling point and for the calculation of enthalpy of evaporation in dependence on the carbon number (Laux et al., 1998). It was found that the correlation coefficients are analogous to those of Kopsch (1995).

The flocculation points of the products as the measure of colloidal stability were determined by a titration method as described in Laux et al. (1997a). A precipitant is added at constant rate to the solution of the petroleum product under intensive stirring. The titration is monitored by a light intensity meter. After flocculation onset the light intensity decreases and the maximum of the curve is defined as the flocculation point. In this case chlorobenzene was used as the solvent and isooctane as the precipitant. The concentration of the solution was $5 \mathrm{wt} \%$.

On the basis of the flocculation point determination it was found that the Flory Huggins interaction parameter $\chi$ can be used as a criterion of stability (Laux et al., 1997a, 1997b):

$$
\chi=\frac{v_{\mathrm{dm}}}{R T}\left(\delta_{\mathrm{as}}-\Delta \delta-\delta_{\mathrm{dm}}\right)^{2} \leq \chi_{\text {crit }}
$$

where:

$\chi \quad$ Flory Huggins interaction parameter

$v_{\mathrm{dm}}$ molar volume of the dispersion medium

$\mathrm{R}$ universal gas constant

$T$ temperature

$\delta_{\text {as }} \quad$ solubility parameter of asphaltenes

$\delta_{\mathrm{dm}}$ solubility parameter of the dispersion medium

$\Delta \delta$ correction term considering the influence of asphaltene solvation

$\chi_{\text {crit }}$ critical Flory Huggins interaction parameter
The solubility parameters of asphaltenes $\delta_{\text {as }}$ were calculated by Equation (4) (Laux, 1992):

$$
\delta=16.55+\left(0.00464+\frac{3.2285}{n_{\mathrm{C}}}\right)\left(z_{\mathrm{Ra}}-2\right)+\Delta \delta_{\mathrm{He}}
$$

According to Equation (4) the solubility parameter is a function of the hydrogen deficit $z_{\mathrm{Ra}}$ in relation to alkanes and of the carbon number $n_{\mathrm{C}} \cdot z_{\mathrm{Ra}}$ is calculated by Equation (5):

$$
z_{\mathrm{Ra}}=0.5\left(2 n_{\mathrm{C}}+2-n_{\mathrm{H}}\right)
$$

The value $\Delta \delta_{\mathrm{He}}$ considering the influence of the heteroatom influence is obtained from Equation (6):

$$
\Delta \delta_{\mathrm{He}}=\rho \sum F_{i} \frac{y_{i}}{A_{i}}
$$

where $\rho$ is the density of the sample, $F_{i}$ is the increment value, $y_{i}$ is the content of heteroatom $i$ and $A_{i}$ is the atomic weight.

At the flocculation point can be accepted:

$$
\delta_{\mathrm{fp}}=\delta_{\mathrm{dm}}
$$

The average solubility parameters of the solvent-precipitant mixture at the flocculation point $\delta_{\mathrm{fp}}$ was determined by Equation (8):

$$
\Delta_{\mathrm{fp}}=\Phi_{\mathrm{s}} \delta_{\mathrm{s}}+\Phi_{\mathrm{p}} \delta_{\mathrm{p}}
$$

$\phi_{\mathrm{s}}$ and $\phi_{\mathrm{p}}$ are volume fractions, $\delta_{\mathrm{s}}$ and $\delta_{\mathrm{p}}$ the solubility parameters of solvent and precipitant.

The differences between the solubility parameter of low soluble asphaltenes and of solvent-precipitant mixture at the flocculation points are given in Table 2.

The small difference of solubility parameters of the visbreaking residue indicates the low colloidal stability of this product. The colloidal stability of the atmospheric and vacuum residues are nearly identical.

TABLE 2

Solubility parameters of the low soluble asphaltenes $\delta_{\text {lsas }}$ and of the solvent-precipitant mixtures at the flocculation point $\delta_{\mathrm{fp}}$ and their differences in $\left(\mathrm{MJm}^{-3}\right)^{0,5}$

\begin{tabular}{l|c|c|c}
\hline \multicolumn{1}{c|}{ Residue } & Atmospheric & Vacuum & Visbreaking \\
\hline$\Delta_{\text {lsas }}$ & 19.98 & 19.92 & 20.45 \\
$\Delta_{\text {fp }}$ & 15.21 & 15.23 & 16.16 \\
\hline Difference & 4.77 & 4.69 & 4.29 \\
\hline
\end{tabular}

\section{RESULTS AND DISCUSSION}

The comparison of the activation energies of the original products and maltenes (Figs. 1 to 3 ) shows that:

- at temperatures up to $375^{\circ} \mathrm{C}$ the original products have higher evaporation enthalpies than their maltenes. The difference increases with the asphaltene content; 
- the influence of asphaltenes on the cracking energy is not significant.

The influence of colloidal stability is represented by the mixtures of the atmospheric and vacuum residues. In Figure 4 the activation energies (evaporation enthalpies) at different temperatures in the region from 300 to $375^{\circ} \mathrm{C}$ are displayed as a function of vacuum residue percentage. It is evident that the evaporation enthalpies show extreme dependencies. A similar behaviour was found for the mixtures of atmospheric residue and the residue of supercritical extraction (Fig. 5).

The flocculation points show a minimum only in dependence on the vacuum residue percentage (Fig. 6).

The thermogravimetric residues at $500^{\circ} \mathrm{C}$ as measure of the coke formation are shown in Figure 7.

The influence on the weight loss by evaporation at different temperatures is demonstrated by Figure 8 . One can conclude that the addition of the components of vacuum residue to the atmospheric residue may lead altogether to increasing distillate yield.

The addition of dispersing agents to the atmospheric and visbreaking residues produces the following results:

- the effects of the dispersing agents are more pronounced in the relatively unstable visbreaking residue than in the atmospheric residue;

- in the case of the visbreaking residue an extreme dependence of activation energies on the concentration of dispersing agent is found (Fig. 9). The corresponding flocculation points are shown in Figure 10;

- the TGA residues at $500^{\circ} \mathrm{C}$ are decreased by addition of dispersing agents (Table 3), but at higher concentrations the residue begins to increase again;

- the distillation yield was not significantly influenced by the dispersing agents.

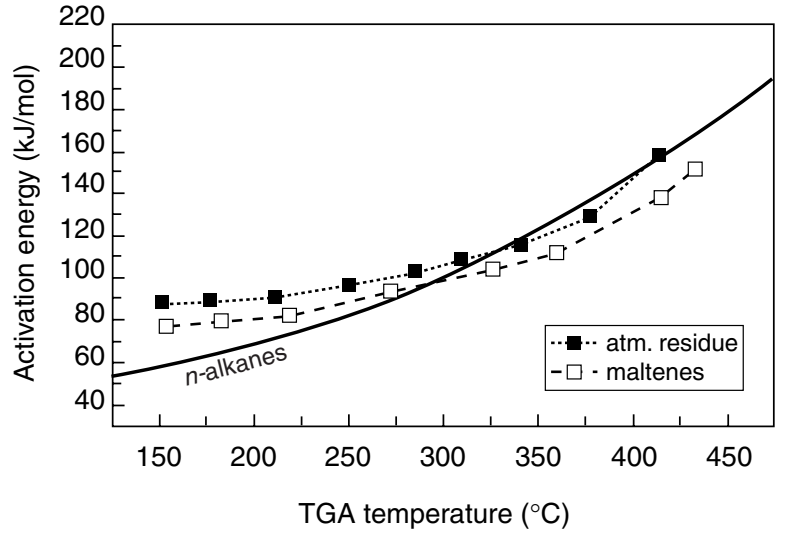

Figure 1

Activation energies of the components of the atmospheric residue.

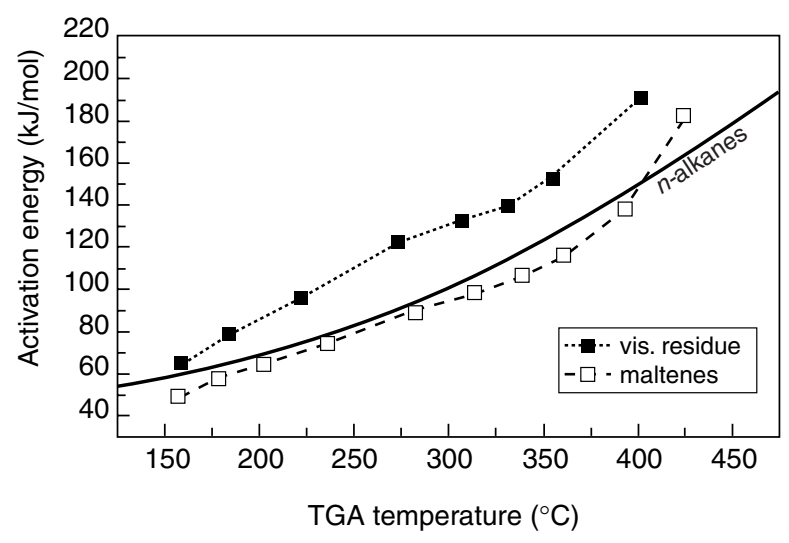

Figure 3

Activation energies of the components of the visbreaking residue.

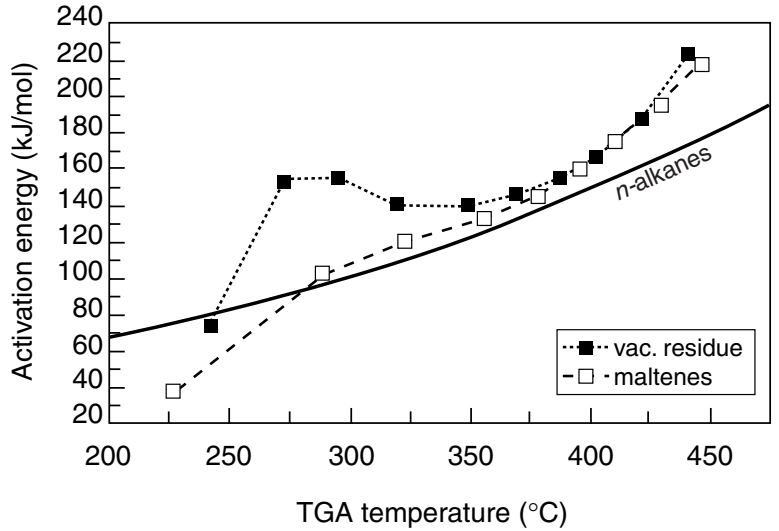

Figure 2

Activation energies of the components of the vacuum residue.

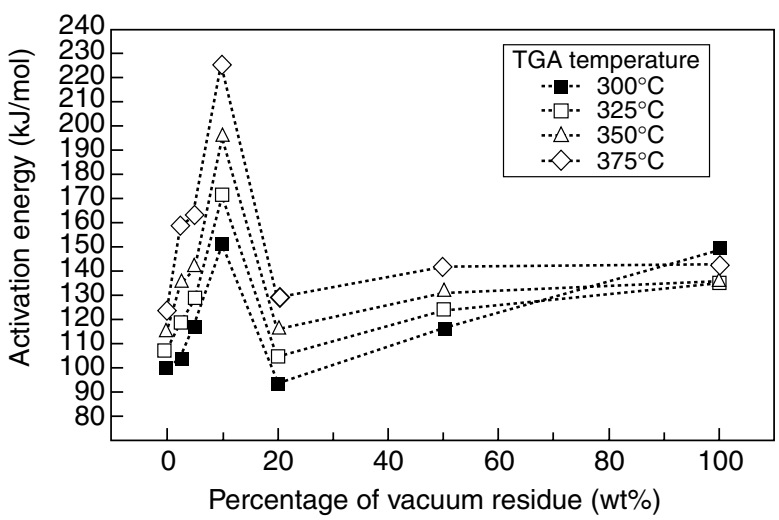

Figure 4

Activation energies of the mixtures of atmospheric and vacuum residues in dependence on the percentage of the vacuum residue. 


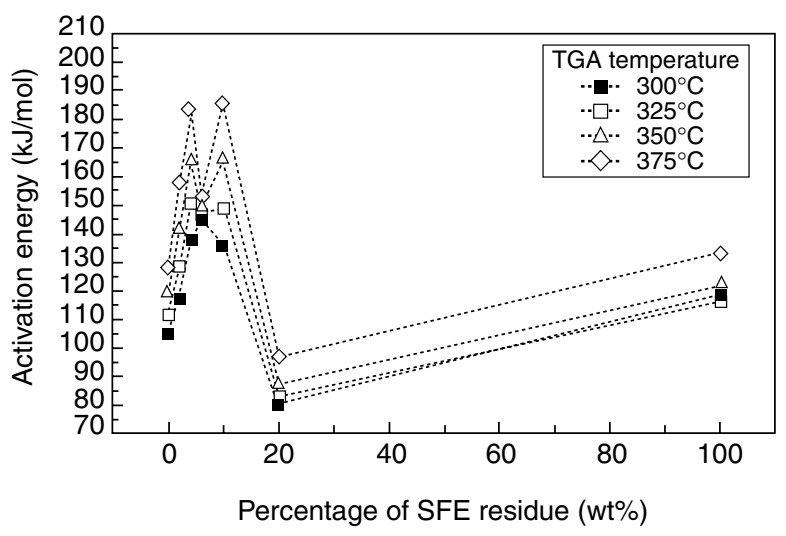

Figure 5

Activation energies of the mixtures of atmospheric and SFE residues in dependence on the percentage of the SFE residue.

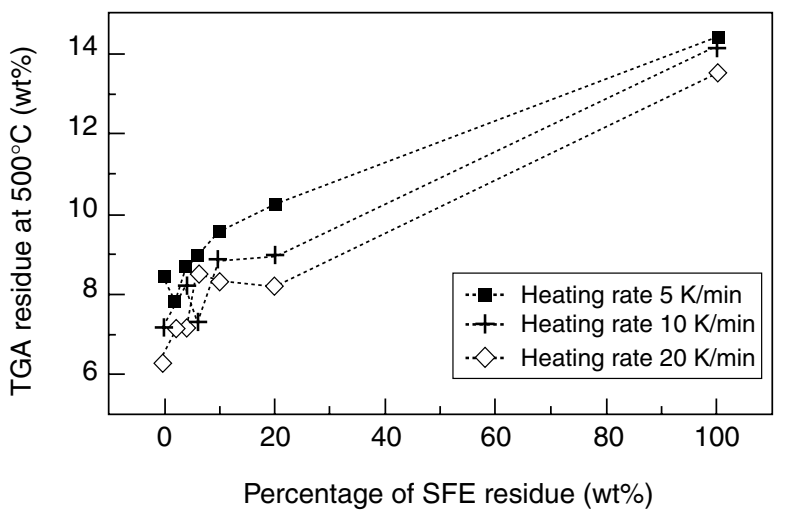

Figure 7

Dependence of the TGA residue at $500^{\circ} \mathrm{C}$ on the percentage of SFE residue in the mixture with the atmospheric residue.

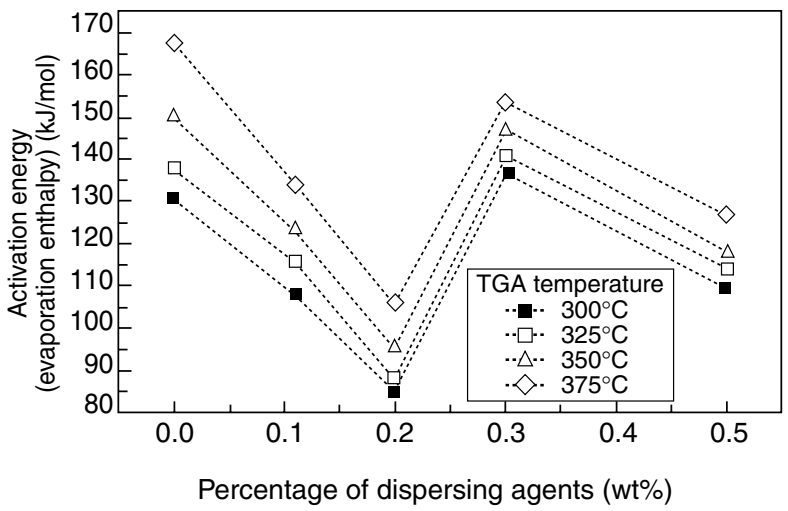

Figure 9

Activation energies of the components of the visbreaking residue in dependence on the dispersing agent concentration.

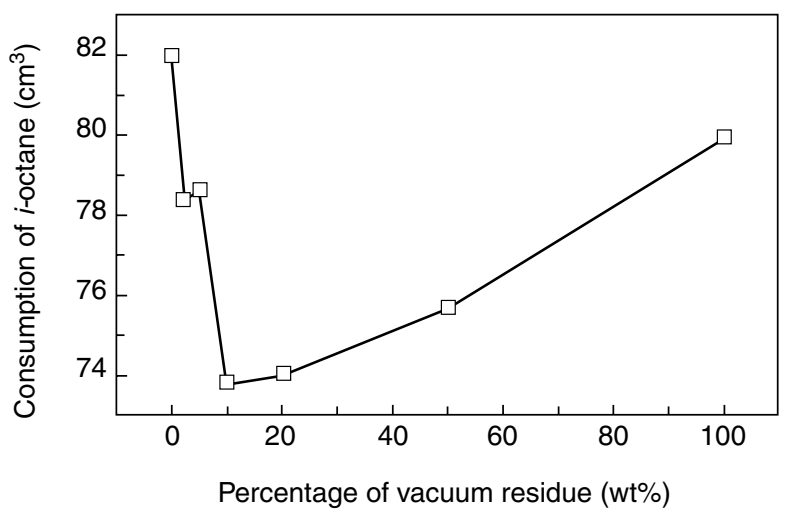

Figure 6

Flocculation points of the mixtures of atmospheric and vacuum residues.

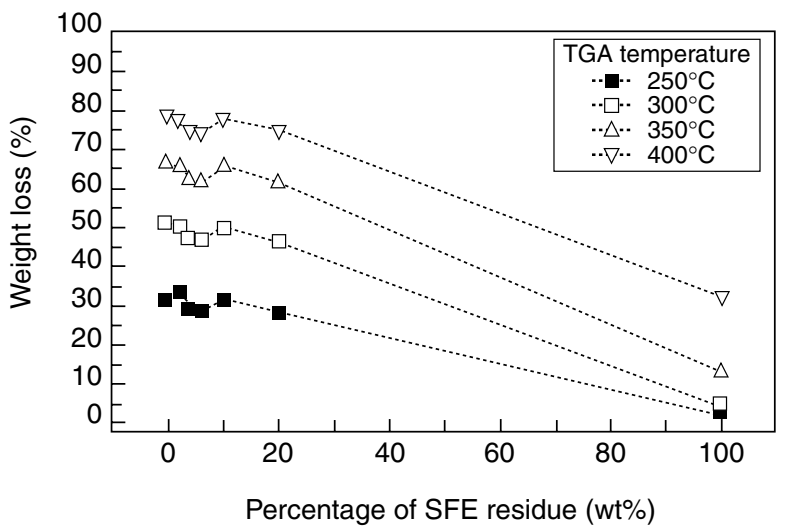

Figure 8

Yields of distillates in dependence on the part of SFE residues in the mixtures with the atmopheric residue.

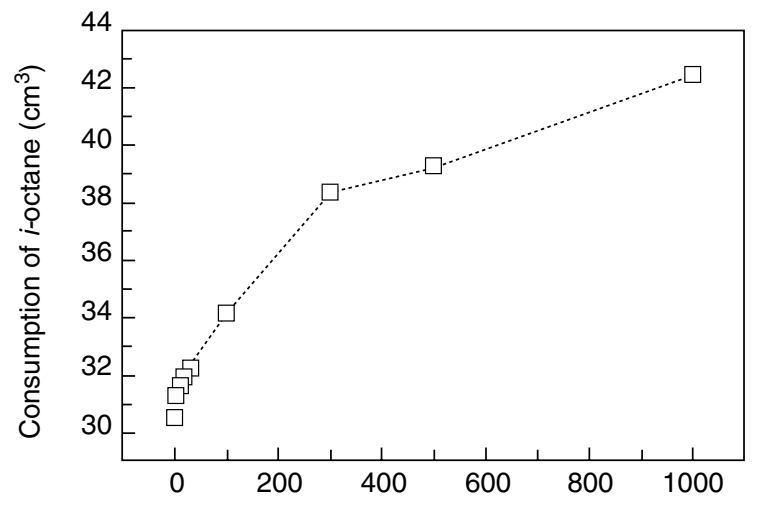

Dispersing agent concentration of solution (ppm)

Figure 10

Flocculation points of the visbreaking residue in dependence on the dispersing agent concentration. 
TABLE 3

Influence of the dispersing agents on the TGA residues at $500^{\circ} \mathrm{C}(\mathrm{wt} \%)$

\begin{tabular}{|c|c|c|c|}
\hline \multirow{2}{*}{$\begin{array}{l}\text { Dispersing } \\
\text { agent }\end{array}$} & \multirow{2}{*}{$\begin{array}{c}\text { Concentration of } \\
\text { dispersing agent } \\
\text { (wt } \%)\end{array}$} & \multicolumn{2}{|c|}{ Residue at $500^{\circ} \mathrm{C}$ of the } \\
\hline & & $\begin{array}{l}\text { atmospheric } \\
\text { residue }\end{array}$ & $\begin{array}{c}\text { visbreaking } \\
\text { residue }\end{array}$ \\
\hline \multirow[t]{5}{*}{$A$} & 0 & 8.4 & 21.5 \\
\hline & 0.1 & 6.9 & 16.0 \\
\hline & 0.2 & & 17.9 \\
\hline & 0.3 & 7.0 & 16.8 \\
\hline & 0.5 & 6.9 & 16.0 \\
\hline \multirow[t]{3}{*}{$B$} & 0.5 & 6.5 & 16.4 \\
\hline & 1.0 & 6.8 & 17.5 \\
\hline & 2.0 & 9.5 & 18.3 \\
\hline
\end{tabular}

Since the difference of the activation energies of the crude oil residues and their dispersion media (maltenes) is a measure of interaction forces between the disperse phase and the components of the dispersion medium we may conclude.

The influences on these interactions are not additive when different crude oil residue products are mixed. Obviously the simultaneous variation of degree of aggregation and degree of solvation of asphaltenes leads to extreme changes. Hereby, a maximum of interaction is found if the flocculation point is minimal. This condition causes also decreased distillate yields and increased coke residues. Such behaviour was also found by Syunayev et al. $(1990,1997)$ while investigating disperse crude oil systems.

The stabilisation by dispersing agents displays other results. In spite of continuously increasing stability the activation energy develops extreme. This behaviour indicates that the mechanisms of stabilisation by dispersing agents on the one hand and by solvation by petroleum components on the other hand have to be distinguished.

\section{CONCLUSION}

It has been shown that the thermogravimetry can be used to investigate the influence of the colloidal phase on the distillation and cracking behaviour of crude oil residues. This influence is exhibited for the activation energies, for the distillation yield and for the cracking residue at $500^{\circ} \mathrm{C}$. The complexity of interactions is illustrated especially by the extreme dependence of evaporation enthalpies on the mixing of residues and on the additivation. Therefore, calculation methods for evaporation enthalpies as have been developed for hydrocarbon mixtures cannot be used in the case of crude oil residues (Laux et al., 1998). The mixing of different crude oil residues and the addition of dispersing agents need an experimental verification, which can be realised by thermogravimetry.

\section{ACKNOWLEDGMENT}

This work was supported through a grant from Deutsche Forschungsgemeinschaft.

\section{REFERENCES}

Flynn, J.H. and Wall, A.L. (1966) A Quick Direct Method for Determination of Activation Energy from Thermogravimetric Data. Polymer Letters, 4, 323-328.

Kopsch, H. (1995) Thermal Methods in Petroleum Analysis, VCH Verlagsgesellschaft, Weinheim.

Laux, H., Butz, T. and Rahimian, I. (1998) Einfluß der kolloiddispersen Phase auf das thermodynamische Verhalten von Erdölrückständen (Influence of Colloid Disperse Phase on the Thermodynamic Behaviour of Crude Oil Residues). Proceedings of DGMK Conference, 30 September, Hamburg-Reinbeck (DGMK-Tagungsbericht 9804), 41-51.

Laux, H. (1992) Löslichkeitsparameter und Verteilung von Erdölrückstanskomponenten (Solubity Parameters and Distribution of Crude Oil Residue Components). Erdöl, Erdgas, Kohle, 108, 227-232.

Laux, H. and Kopsch, H. (1996) Verdampfungsenthalpien höher siedender Erdölkomponenten (Evaporation Enthalpies of Higher Boiling Crude Oil Components). Chem. Techn., 48, 267-270.

Laux, H., Rahimian, I. and Butz, T. (1997a) Thermodynamics and Mechanism of Stabilization and Precipitation of Petroleum Colloids. Fuel Proc. Techn., 53, 69-79.

Laux, H., Rahimian, I. and Butz, T. (1997b) Phase Behaviour of Colloidal Crude Oil System. Revue de l'Institut français $d u$ pétrole, 52, 2, 226-227.

Laux, H., Rahimian, I. and Schorling, P. (1999) The Colloidal State of Residues in Dependence of the Crude Oil Processing. Petrol. Sci. and Techn., 17, 3-4, 349-368.

Neumann, H.J. and Wilkens, J. (1974) Methode zur Bestimmung der Asphaltene und Erdölharze in Bitumen und Rückstandsölen (Method for the Determination of Asphaltenes and Petroleum Resins in Bitumen and Distillation Residues). Bitumen, Teer, Asphalte und Pech, 25, 246-247.

Syunyaev, R., Safieva, R. and Syunyaev, Z. (1997) The NonLinear Behaviour of Oil Disperse Systems at the Technological Processes of Oil Industry. Revue de l'Institut français du pétrole, 52, 2, 240-241.

Syunyaev, Z.I., Syunyaev, R.Z. and Safieva, R.Z. (1990) Neftjanye dispersnye sistemy (Disperse Petroleum Systems), Chimija, Moscow (in Russian).

Zenke, G. (1989) Zum Löseverhalten von Asphaltenen. Anwendung von Löslichkeitsparameter-Konzepten auf Kolloidfraktionen schwerer Erdölprodukte (About the Solubility Behaviour of Asphaltenes. Application of Solubility Parameter Concepts on Colloidal Fractions of Heavy Petroleum Products). PhD Thesis, Technical University of Clausthal.

Zou, R. and Lin, L. (1994) Role of Asphaltenes in Petroleum Cracking and Refining, in Asphaltenes and Asphalts, 1, Yen, T.F. and Chiligarian, G.V. (eds.), Elsevier, Amsterdam, 339-363.

Final manuscript received in February 2000 